\title{
Restful Web Service Sistem Presensi Mahasiswa (Studi Kasus Fakultas Teknologi Informasi dan Komunikasi Universitas Semarang)
}

\author{
Dewi Nurdiyah ${ }^{1}$, Sri Handayani ${ }^{2}$ \\ ${ }^{1}$ Program Studi Informatika Fakultas Teknologi Informasi \& Komunikasi, Universitas Semarang \\ Jl. Soekarno-Hatta, Semarang 50196, e-mail: nurdiyah@usm.ac.id \\ ${ }_{2}$ Program Studi Informatika Fakultas Teknologi Informasi \& Komunikasi, Universitas Semarang \\ Jl. Soekarno - Hatta, Semarang 50196, e-mail: sri@usm.ac.id
}

\section{ARTICLE INFO}

Article history:

Received 30 December 2017

Received in revised form 30 December 2017

Accepted 05 January 2018

Available online 25 January 2018

\section{ABSTRACT}

The Student attendance at the Faculty of Information Technology and Communication University of Semarang is data that can support in academic activities. validity and realbility of the attendance data become obstacles in academic activities. So, Required attendance system that can prevent the occurrence of cheating attendance, facilitate lecturers to recap student attendance and facilitate administrative staff to recap lecturers's attendance. In this research, student attendance system is made with two platforms, there are web based platform and platform based on android. Restful web service with JSON format is used to build communication between both platforms. In the attendence system android based, QRCode's Reader is used to read student QRCode cards to save attendance data. student dan lecture attendance can be monitored through attendance system web based. The attendance system test is done by testing all of the features and complexity of the algorithm with cyclomatic complexity. The test results show that all features can be used without error and cyclomatic complexity value show that algorithm of the attendance system is easy to understand, easy to test and easy to maintain.

Keywords: Sistem Presensi Mahasiswa,Restful Web Service, QR Code Reader

\section{Pendahuluan}

Dokumen otentik bahwa penyelenggaraan akademik berlangsung di kelas adalah dokumen presensi mahasiswa. Dalam dokumen presensi terdapat informasi penting mengenai jadwal kuliah, kehadiran dosen yang dapat dilihat dari matrik kuliah, materi yang diajarkan dosen dan keaktifan kehadiran mahasiswa. Sehingga, presensi mahasiswa memiliki peranan penting dalam penyelenggaraan akademik. Fakultas Teknologi Informasi dan Komunikasi Universitas Semarnag (FTIK USM) memiliki kendala dalam mengelola presensi mahasiswa, kendala yang sering terjadi 
dalam presensi mahasiswa adalah berkas presensi dapat rusak karena harus selalu diedarkan ke mahasiswa saat perkuliahan berlangsung. Faktor kecurangan tidak dapat dihindari seperti rekayasa kehadiran mengajar dosen dan rekayasa tanda tangan presensi mahasiswa. Oleh karena itu, monitoring kehadiran mengajar dosen selalu direkap oleh pegawai TU (Tata Usaha) FTIK untuk memantau kehadiran dosen dan menentukan honor mengajar dosen sesuai dengan kehadirannya. Akan tetapi, pada prakteknya pegawai TU kesulitan untuk mengumpulkan dokumen presensi setiap bulannya karna harus meminjam dokumen presensi ke dosen pengampu matakuliah. Dari masalah tersebut, diperlukan alat yang secara realtime dapat membantu mencatat presesi kehadiran mahasiswa, kehadiran dosen dan semua data presensi dapat terrekap otomatis dan dapat digunakan kapanpun saat dibutuhkan.

Saat ini masyarakat sangat familiar mengoperasikan smartphone berbasis android. Sehingga, pada penelitian ini smartphone berbasis android dijadikan sebagai perangkat untuk presensi mahasiswa. Untuk menyimpan data prensensi diperlukan database server berbasis web yang terpusat agar seluruh data presensi tersimpan ditempat yang sama. Sehingga, diperlukan Restful web service untuk melakukan request respon antara sistem presensi berbasis android ke sistem berbasis web. Pertukaran data antar kedua system tersebut menggunakan key unik yang dimiliki oleh mahasiswa yaitu nim. Agar presensi dapat dibaca dengan cepat dengan sistem maka nim mahasiswa dapat dijadikan QRCode kemudian dibaca menggunakan aplikasi presensi dengan QRCode Reader berbasis android.

\section{Penelitian Terkait}

QRCode telah banyak digunakan pada penelitian sebelumnya untuk identifikasi. Diantaranya, identifikasi aset TIK menggunakan QRCode berbasis android[1], aplikasi tiketing berbasis android[3], indentifikasi identitas siswa [4], pelabelan dokumen[5], identifikasi dan manajemen kendaraan di ITS[6]. Untuk membaca kode QR Code diperlukan QR Code Reader atau QR Code Scanner. Saat ini, QR Code tidak hanya dapat menyimpan data teks. Penelitian yang dilakukan oleh M Pasca Nugraha dan Rinaldi Munir, QR Code dapat menyimpan data gambar dan membaca data gambar tersebut dengan QR Code Reader [8].

Penggunaan Restful Web Service telah dilakukan pada penelitian sebelumnya. Diantaranya, untuk monitoring sistem drainase, data debit air dan curah hujan dikirm secara realtime dari sensor ke web server. Agar komunikasi dapat berjalan maka diperlukan Restful Web Service melalui link Http[2]. Penelitian mengenai Rest-API juga telah dilakukan untuk portal akademik UKDW berbasis android. Data disimpan dan diambil dari database server sehingga diperlukan Rest-API agar komunikasi antar kedua platform tersebut dapat berjalan[10].

\section{Metode Penelitian}

Prototyping merupakan salah satu metode pengembangan sistem. Metode prototype dipilih agar pengembangan sistem dapat dilakukan dengan akurat karena setiap proses pengembangan dilakukan evaluasi untuk memastikan sistem presensi dapat berjalan dengan baik dan benar. Sedangkan teknologi yang digunakan untuk mengembangkan sistem presensi mahasiswa adalah Rest Web Service. Dengan teknologi Restful maka sistem presensi yang berjalan di platform berbasis web dan platform berbasis android dapat saling melakukan request respon data presensi. Berikut gambaran umum restful web service sistem presensi mahasiswa. 


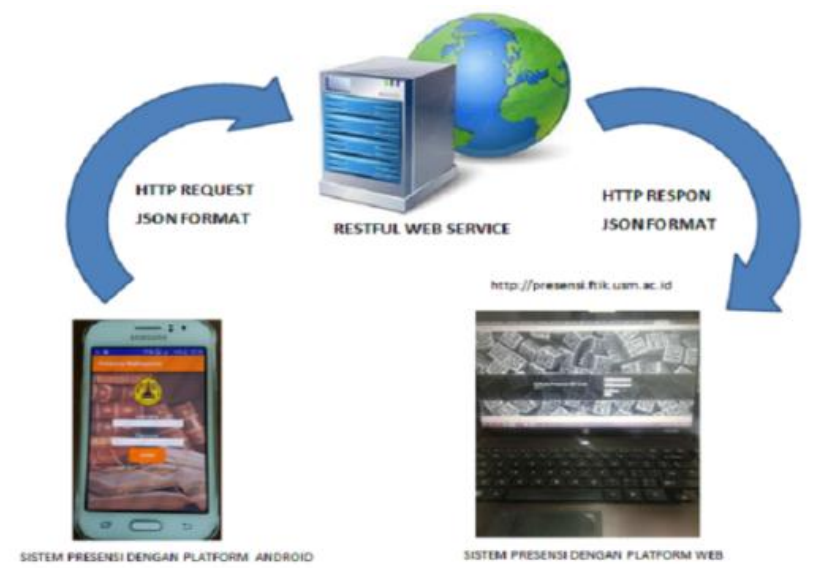

Gambar 1. Teknologi Restful Web Service Sistem Presensi Mahasiswa

Sistem presensi mahasiswa berjalan di dua platform yaitu platform berbasis web dibangun dengan bahasa pemrograman PHP, JSON dan database MySQL. Platform berbaiss android dibangun dengan bahasa pemrograman java, xml dan JSON. Sistem presensi berbasis android digunakan oleh dosen untuk menginputkan jadwal kuliah yang sedang berlangsung dikelas, kemudian mahasiswa melakukan presensi dengan cara scan kartu QR Code mahasiswa dengan QR Code Reader berbasis android. Data presensi akan dikirimkan secara realtime ke server. Secara realtime pula dengan mengakses alamat sistem presensi berbasis web http://presensi.ftik.usm.ac.id pegawai tata usaha FTIK dapat memantau kehadiran dosen untuk perhitungan gaji dosen berdasarkan kehadiranya dikelas. Dengan adanya Restful Web Service, kedua platform ini dapat saling berkomunikasi untuk melakukan request respon data presensi dengan format JSON. Berikut usecase diagram yang menggambarkan aktor-aktor yang menggunakan sistem presensi mahasiswa.

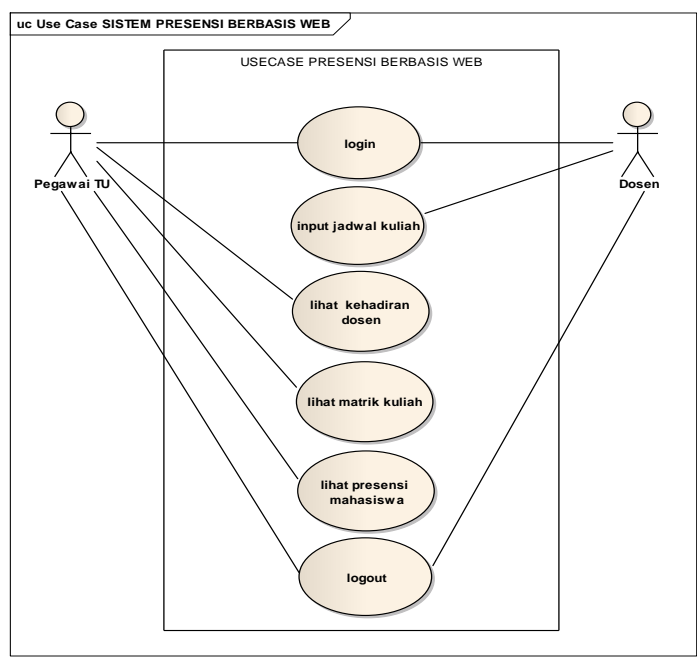

Figure 2. Usecase diagram sistem presensi berbasis web

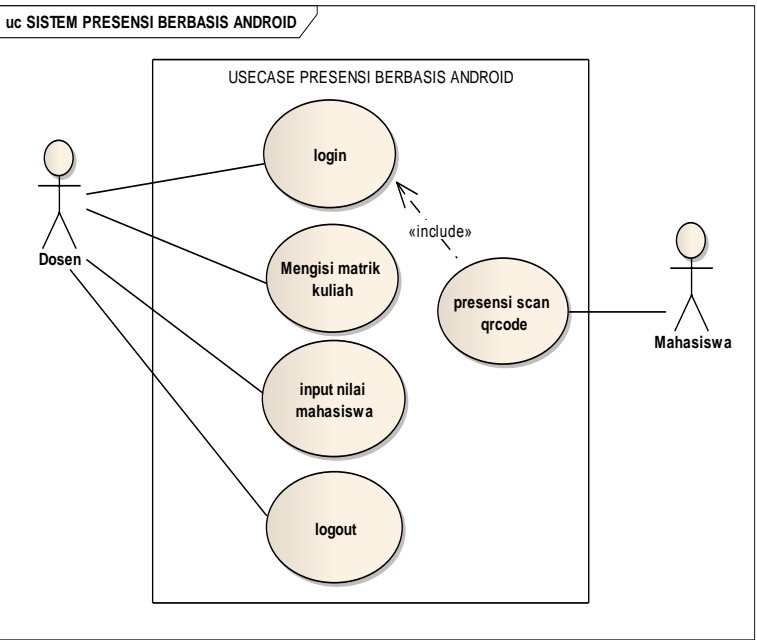

Figure 3. Usecase diagram sistem presensi berbasis android

TRANSFORMATIKA Vol. 15, No. 2, Januari 2018: $60-66$ 


\section{Hasil dan Pembahasan}

Pengujian sistem presensi mahasiswa dilakukan dengan dua cara yaitu black box testing dan white box testing. Pengujian black box testing dilakukan dengan menguji fungsionalitas fitur-fitur sistem dengan GUI (Graphical User Interface).

\subsection{Black box testing sistem presensi berbasis web}

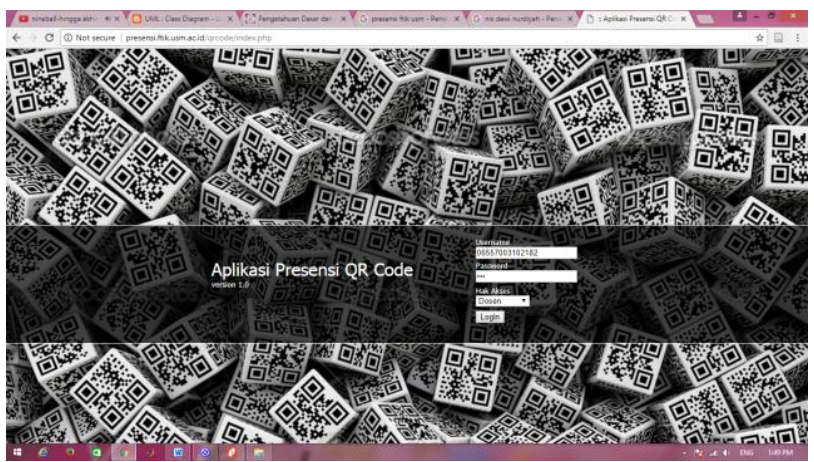

Gambar 4. Login sistem presensi berabasis web

Halaman login sistem presensi berbasis web seperti pada gambar 4. Dapat berfungsi dengan baik tanpa error. Login sistem digunakan untuk keamanan serta untuk membedakan otoritas pemberian fitur untuk dosen dan pegawai TU.

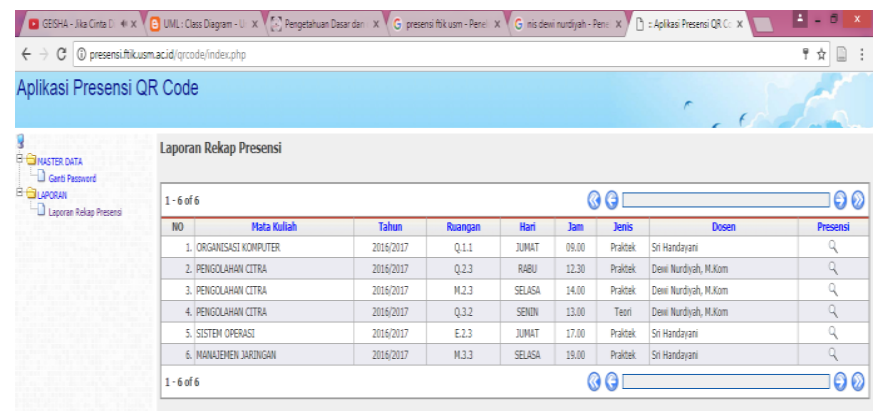

Gambar 5. Rekap kehadiran mahasiswa

Rekap kehadiran mahasiswa dapat dilihat oleh dosen. Dan TU dapat merekap kehadiran dosen berdasarkan kehadiran mahasiswa ditunjukkan seperti pada gambar 5. Fitur ini dapat berjalan dengan baik tanpa error. Perbedaan fitur dosen dan pegawai TU adalah dosen dapat mengimport jadwal mengajarnya sesuai dengan jadwal yang tertera di sistem informasi akademik http://sia.usm.ac.id sedangkan pegawai TU tidak biasa.

\subsection{Black box testing sistem presensi berbasis android}

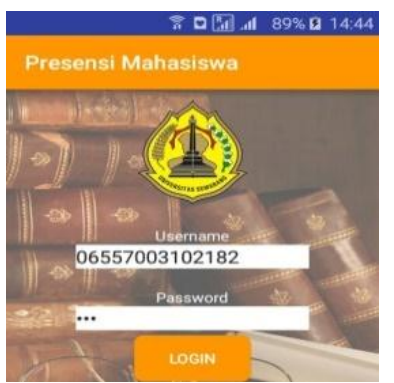

Restful Web Service Sistem Presensi Mahasiswa (Studi Kasus Fakultas Teknologi Informasi dan Komunikasi (Dewi Nurdiyah) 
Gambar 6. Login dosen

Halaman login dosen dapat berfungsi dengan baik tanpa error seperti pada gambar 6 .

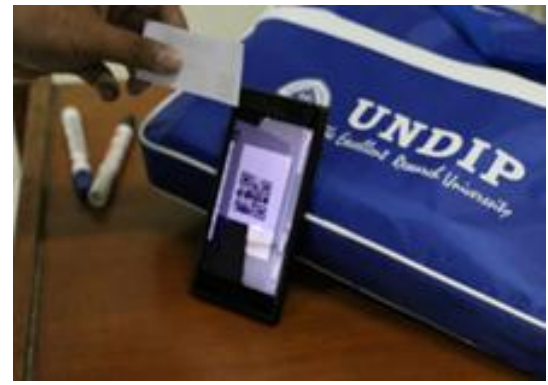

Gambar 7. Scan QRCode untuk presensi mahasiswa

Scan QR Code mahasiswa seperti pada gambar 7. Dapat dilakukan jika dosen sudah melakukan login. Setelah mahasiswa melakukan login data akan disimpan secara realtime di database server.

\subsection{White box testing sistem presensi berbasis android}

Pengujian prosedur program digunakan untuk mengukur kompleksitas algoritma yang berdampak pada waktu eksekusi program. Pada penelitian ini, cyclomatic complexity digunakan untuk mengukur kompleksitas algoritma. Prosedur program pada proses pembacaan QRcode untuk presensi mahasiswa ditunjukkan pada gambar 8 .

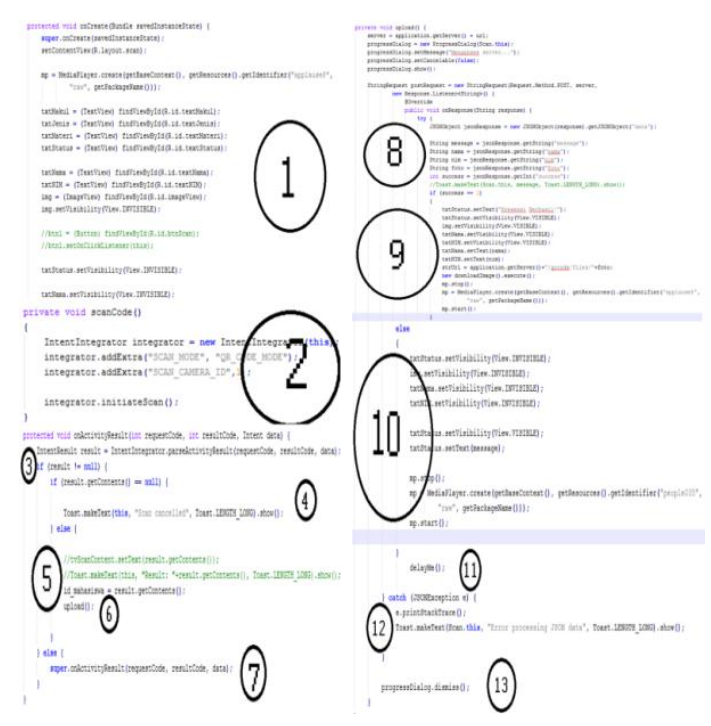

Gambar 8. Prosedur program pembacaan $Q R$ Code untuk presensi mahasiswa
Kompleksitas algoritma dari gambar 8 divisualisasikan dengan flow graph gambar 9

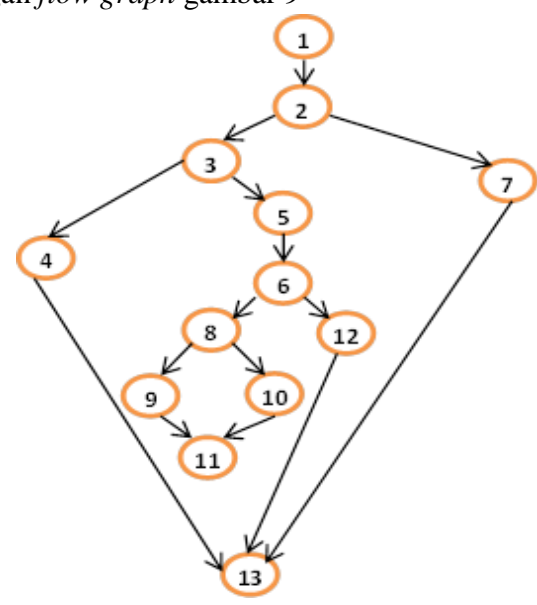

Gambar 9. Flow graph pembacaan QR Code

Besarnya cyclomatic complexity dari flow graph gambar 20 adalah 5. Artinya, terdapat lima jalur basis path pada listing program presensi scan QR Code kehadiran mahasiswa.

Jalur basis path sebagai berikut :

1. $1-2-3-4-13$

2. $1-3-5-6-8-9-11-13$

3. $1-2-3-5-6-8-10-11-13$

4. $1-2-3-5-6-12-13$

5. $1-2-7-13$

TRANSFORMATIKA Vol. 15, No. 2, Januari 2018: $60-66$ 
Besarnya nilai cyclomatic complexity mempengaruhi risiko yang terjadi dalam listing program diantaranya kesulitan pemahaman program, kesulitan pengujian dan kesulitan pemeliharaan[11].

Tabel 1. Pengaruh Nilai Cyclomatic Complexity Terhadap Risiko [11]

\begin{tabular}{lll}
\hline Nilai CC & Tipe prosedur & Risiko \\
\hline $1-4$ & $\begin{array}{l}\text { Prosedur sederhana } \\
5-10\end{array}$ & $\begin{array}{l}\text { Struture baik dan } \\
\text { prosedur } \\
\text { rendah }\end{array}$ \\
$\begin{array}{l}\text { yang stabil } \\
\text { 11-20 } \\
\text { Prosedur yang banyak } \\
\text { dan kompleks }\end{array}$ & sedang \\
\hline
\end{tabular}

\section{Kesimpulan}

Restful Web Service dapat dimanfaatkan untuk membangun komunikasi request respon antar sistem yang berbeda, yaitu sistem presensi berbasis android dengan sistem presensi berbasis web. Kehadiran mahasiswa dan kehadiran dosen dapat dipantau secara realtime dengan sistem presensi. Sehingga bermanfaat untuk mencatat kedisiplinan kehadiran mahasiswa saat proses perkuliahan, mencegah terjadinya kecurangan pengisian presensi mahasiswa dan rekapitulasi kehadiran dosen dapat di-generate otomatis sehingga mempermudah pekerjaan pegawai TU FTIK USM.

\section{Acknowledgement}

Terimakasih kepada Diretorat Riset dan Pengabdian Kepada Masyarakat yang telah mendanai penelitian ini melalui skema Penelitian Dosen Pemula tahun 2016 yang bertujuan membangun sistem presensi mahasiswa yang dapat berjalan secara realtime di Fakultas Teknologi Informasi dan Komunikasi Universitas Semarang.

\section{Referensi}

[1] Dery Susilo, Marcel. "Rancang Bangun Aplikasi Identifikasi Aset TIK Menggunakan QR Code Berbasis Android Studi Kasus Laboratorium Komputer UKRIDA Kampus I". Seminar Nasional Aplikasi Teknologi Informasi ISSN : 1907-5022. 2015

[2] Dini Nurmalasari, dkk. "Informational Dashboard Untuk Monitoring Sistem Drainase Secara Real Time". Jurnal Teknik Elektro dan Teknologi Informasi Vol.4 No.3.2015

[3] Frengky Tedy. "Pengembangan Aplikasi Tiketing Berbasis QR Code Dengan Data Terenkripsi Untuk Stadion Utama Gelora Bung Karno". Tesis Program Megister Teknik Informatika Universitas Atma Jaya Yogyakarta. 2013

[4] Md-Saunal Haque, Ricard Dybowski. 2014. "Andvance QR Code Based Indentity Card New Era For Generating Student ID Card In Developing Country". Journal IEEE DOI.10.1109/SISMS.24. 2014

[5] Mita Pramihapsari, Messa Prima Kaldera. "Perancangan Labelling Pada Dokumen Menggunakan QR Code”. Jurnal Teknik Komputer Vol:20 No:1. 2012

[6] Muhammad, dkk. "Perancangan dan Implementasi Perangkat Lunak Untuk Identifikasi dan Manajemen Kendaraan di ITS pada Perangkat Bergerak dengan Teknologi QR Code". Jurnal Teknik POMITS Vol:2 No:1. 2013

[7] Mukhammad Taqwa Nuddin, Diana Laily Fithri. "Sistem Absensi Asisten Dosen Menggunakan QR Code Scanner Berbasis Android Pada Program Studi Sistem Informasi Universitas Muria Kudus”. Prosiding SNATIF ISSN : 978-602-1180-21-1. 2015 
[8] M Pasca Nugraha, Dr.Ir.Rinaldi Munir, M.T. "Pengembangan Aplikasi QR Code Generator dan $Q R$ Code Reader Dari Data Berbentuk Image". Konferensi Nasional KNIF ISSN : 20873328. 2011

[9] Rizky Meimaharani, Diana Laily. "Perancangan E-Commerce Goody Bag Spunbond Menggunakan QR Code Berbasis Web Responsif". Prosiding SNATIF ISSN : 978-6021180-04-4. 2014

[10] Yosef Koko Kurniawan, dkk. "Implementasi REST-API Untuk Portal Akademik UKDW "Berbasis Android". Jurnal EKSIS Vol:6 No:2. 2013

[11] Complexity Metrics. "Value Of Cyclomatic Complexity" . 9 oktober 2017. http://www.aivosto.com/project/help/pm-complexity.html

TRANSFORMATIKA Vol. 15, No. 2, Januari 2018: $60-66$ 